\title{
Cheiroarthropathy and long term diabetic complications in Nigerians
}

\begin{abstract}
Two hundred and fifty six consecutively ambulant diabetic patients attending a Nigerian diabetic clinic for the presence of cheiroarthropathy were examined using standard criteria. Forty eight (19\%) had limited joint mobility of the hand, a prevalence higher than the $4 \%(2 / 56)$ observed in a non-diabetic population matched for age and sex. Limited joint mobility was twice as prevalent in the insulin treated $(16 / 50,32 \%)$ than in the noninsulin dependent $(32 / 206,16 \%)$ diabetics. Indices such as age, duration of diabetes, and glycaemic control (as assessed by integrated blood glucose concentration over the previous 12 months and glycated haemoglobin $\left(\mathrm{HbA}_{1 \mathrm{c}}\right.$ concentrations) were the same in the diabetics with and without limited joint mobility. The prevalence of cataracts $(18 / 48,38 \%)$ and background retinopathy $(8 / 48,17 \%)$ was higher in diabetics with limited joint mobility than in those without (respectively $6-9 \%$ and $5-6 \%$ ); hypertension, peripheral neuropathy, and foot ulcers, however, were about equally common in the two groups of diabetics (with and without limited joint mobility). Nephropathy appeared commoner in diabetic subjects without limited joint mobility. Our results confirm previous observations in Caucasians of an increased prevalence of limited joint mobility in diabetes, especially those receiving insulin treatment, and also showed that limited joint mobility could predict the presence of retinopathy and cataracts in those diabetics. Neuropathy and hypertension were not commoner in our diabetics with limited joint mobility (unlike in the Caucasian population), suggesting that racial factors may underlie the predictive value of limited joint mobility in diabetic microangiopathy.
\end{abstract}

The syndrome of limited joint mobility or cheiroarthropathy affecting the small joints of the hands is widely believed to be commoner in diabetic subjects. ${ }^{1-3}$ The aetiopathogenesis remains unknown, but suggested mechanisms include neuropathy, ${ }^{4}$ microangiopathy affecting dermal capillaries and arterioles, ${ }^{5}$ qualitative abnormalities of collagen, ${ }^{6}$ and, more recently, increased non-enzymatic glycation of the collagen in subcutaneous tissue. ${ }^{7}$ Relations have been described between the presence of limited joint mobility and the susceptibility to microvascular complications in diabetes. Neuropathy and retinopathy appear to be commoner in diabetics with limited joint mobility than in those without, ${ }^{125}$ though Chapple et al sug- gested that limited joint mobility did not necessarily predict any of the grades of retinopathy. ${ }^{8}$ The relation with nephropathy is less clear. ${ }^{1}$ Factors that may influence the association of limited joint mobility with the diabetic microvascular complication include age of patient, duration of diabetes, glycaemic control, and need or otherwise for regular insulin treatment. ${ }^{1}$

All the previous studies have been of Caucasian diabetic subjects, and none to our knowledge has been done in tropical or African countries, where prevalence of diabetes appears to be increasing. ${ }^{9}$ Similarly, there have been no reports specifically directed at reviewing other manifestations of limited joint mobility, such as frozen shoulder, in Nigerian or other African subjects, diabetic or not. Moreover, there is little or no general information on the range of joint mobility in black Africans. Such studies are necessary because racial or genetic factors have been suggested as underlying the different prevalence of limited joint mobility observed in Italians and Australians. ${ }^{10}$ Furthermore, in tropical populations where facilities for effective management of the diabetic long term implications are often unavailable or expensive, it is imperative to predict those complications rapidly and easily in order to formulate effective preventive strategies.

We therefore assessed the prevalence of limited joint mobility in a Nigerian diabetic population in relation to clinical indices of the diabetic microvascular complications and other complications. Such rapid and easy office/clinic assessment should offer valuable information on the diabetic patients at risk of microvascular complications and justify special attention to that group.

Subjects and methods

Eight hundred and sixty two diabetic patients regularly attend the diabetic clinic at the University College Hospital, Ibadan. Of this number, $187(21.6 \%)$ are insulin treated. We reviewed 256 consecutively presenting ambulant patients (140 men, 116 women) over a three month period from January to March 1988. Fifty $(20 \%)$ were insulin treated. All were interviewed and examined for (a) peripheral neuropathy: assessed clinically by history of pain, paraesthesiae, burning of hypoaethesiae with signs of absent ankle jerks and reduced vibration sensibility over the lateral malleoli; (b) hypertension with diastolic blood pressure $>95 \mathrm{mmHg}$ using a stan- 
dard mercury gauge sphygmomanometer or otherwise in patients already taking antihypertensive drugs; $(c)$ cataracts and retinopathy by ophthalmoscopy on undilated pupils in a dark room by a doctor experienced in diabetes. Background retinopathy included microaneurysms and non-macular haemorrhages and exudates; any other presentation was considered advanced; (d) albuminuria, assessed by Albustix (Ames); (e) indolent foot ulceration.

Additionally, all were questioned for occupation, previous liver disease, trauma to hands, family history of Dupuytren's contracture, arthritis, or primary joint disease.

Fifty six (28 male) other non-diabetic subjects were recruited from the population of non-diabetic patients in hospital and hospital and laboratory staff with a similar socioeconomic background to that of the diabetic subjects but without a personal or family history of liver disease, arthritis, or diabetes. These control subjects were matched for sex ratio, age, and occupation with the diabetic patients. Most (24) of the women were petty traders, and most (22) of the men were either peasant farmers or unskilled manual workers and artisans, in keeping with the general pattern of occupations of patients attending our diabetic clinics.

Cheiroarthropathy was considered present using the criteria of Rosenbloom et $a l^{2}:(a)$ inability to approximate the palms of the hands and of the fingers to bend backwards; (b) positive prayer sign (inability to oppose the two hands firmly together) or table test (inability to place the hands flat on a table).

Diabetic control was assessed by calculating the mean whole blood glucose concentration over the previous 12 months (or since diagnosis if diabetic for less than one year). A further index for glycaemic control, glycated haemoglobin $\left(\mathrm{HbA}_{1 \mathrm{c}}\right)$ estimation, was done in some of the subjects (randomly selected from the diabetic population with and without limited joint mobility).

Whole blood glucose was measured by a glucose oxidase method and $\mathrm{HbA}_{\mathrm{lc}}$ by affinity chromatography with Glyco-haemoglobin kits (Sigma, St Louis, Missouri, USA). Results are expressed as means (SD). Comparisons between groups were by $\chi^{2}$ tests. The level of significance was $\mathrm{p}<0.05$.

\section{Results}

Forty eight of the 256 diabetic patients (19\%) had limited joint mobility-30 women (aged $54 \cdot 1$ (SD 11.9) years) and 18 men (50.9 (14.1) years). Sixteen of these were insulin treated while the other 32 were non-insulin dependent (diet or oral sulphonylureas, or both). Twenty seven of these patients (all women) were petty traders, 11 peasant farmers, six teachers (including three women), and four missionaries. None had a previous history of liver disease or arthritis, family history of hand contracture, or previous trauma to the hand. They had been diabetic for $6.5(5.8)$ years (range one month-26 years). None of the patients knew for certain whether limited joint mobility antedated diagnosis of diabetes, and this was not always reflected in the case notes. None felt particularly incapacitated by the deformity. Indeed $30(63 \%)$ of those afflicted became aware of limited joint mobility only when it was pointed out to them.

Only two of the $56(4 \%)$ non-diabetic control subjects (aged $45 \cdot 6(12 \cdot 1)$ years) had limited joint mobility. This prevalence was significantly $(p<0.01)$ less than the prevalence in the diabetics.

Mean blood glucose concentration (over 12 months) in those diabetics with limited joint mobility $(14 \cdot 1(4 \cdot 8) \mathrm{mmol} / \mathrm{l})$ was not significantly different from that in the patients without limited joint mobility $(15.9(4 \cdot 2) \mathrm{mmol} / \mathrm{l})$. Also, the $\mathrm{HbA}_{\mathrm{lc}}$ concentrations in those with limited joint mobility $(n=25,114(35) \mathrm{g} / \mathrm{l})$ were not significantly different from the values observed in those without limited joint mobility $(\mathrm{n}=30,121(46) \mathrm{g} / \mathrm{l})$.

The table shows the pattern of diabetic complications in those diabetic patients with limited joint mobility in comparison with findings in 150 diabetic subjects without limited joint mobility studied and earlier reported figures on diabetic complications in Nigerians. ${ }^{11} 12$ The prevalences of peripheral neuropathy, hypertenion, and foot ulceration were not significantly different between subjects with and without limited joint mobility. Cataracts and background retinopathy, however, were two to three times $(p<0.01)$ more prevalent in diabetic patients with limited joint mobility than in those without. The subjects with limited joint mobility appeared to have a lower prevalence of nephropathy than those without $(p<0.01)$, though the only index of nephropathy used here was the persistence of non-infective, afebrile, Albustix positive albuminuria.

\section{Discussion}

Our results confirm previous observations in Caucasians of an increased prevalence of

Pattern of long term complications in Nigerian diabetic subjects with and without cheiroarthropathy

\begin{tabular}{|c|c|c|c|c|}
\hline & $\begin{array}{l}\text { Diabetic subjects with } \\
L \mathcal{F} M^{*}(n=48) \\
\text { No }(\%)\end{array}$ & $\begin{array}{l}\text { Diabetic subjects without } \\
L \mathcal{L M}(n=150) \\
(\%)\end{array}$ & $\begin{array}{l}\text { Reported figures in } \\
\text { unselected Nigerian } \\
\text { diabetics }{ }^{11}(n=832) \\
(\%)\end{array}$ & p Valuet \\
\hline $\begin{array}{l}\text { Peripheral neuropathy } \\
\text { Cataracts } \\
\text { Hypertension } \\
\text { Background retinopathy } \\
\text { Foot ulcers } \\
\text { Persistent non-febrile non- }\end{array}$ & $\begin{aligned} & 26(54) \\
& 18(38) \\
& 14(29) \\
& 8(17) \\
& 4(8)\end{aligned}$ & $\begin{array}{r}40 \\
6 \\
30 \\
6 \\
5\end{array}$ & $\begin{array}{r}48 \\
9 \\
24 \\
5 \\
3\end{array}$ & $\begin{array}{l}\text { NS } \\
0.01 \\
\text { NS } \\
0.01 \\
\text { NS }\end{array}$ \\
\hline infective albuminuria & $1(2)$ & 9 & 19 & 0.05 \\
\hline
\end{tabular}

*LJM=limited joint mobility of the hand.

tp Value expressed in relation to comparisons between diabetic subjects with and without cheiroarthropathy. 
limited joint mobility in diabetics. Nineteen per cent of all diabetics were affected in comparison with only $4 \%$ of a non-diabetic population matched for age. When the figures were expressed in relation to the population at risk, $16 / 50$ insulin treated $(32 \%)$ had a twice greater prevalence than the non-insulin treated (32/ 206, 16\%) diabetics. This trend is in agreement with the earlier reports on limited joint mobility, ${ }^{1-3}$ in which the insulin treated patients had a higher prevalence of $30-40 \%^{3} 8$ than the non-insulin dependent Caucasian diabetics, in whom prevalence varied widely, from 4 to $70 \%^{15}$. In many instances limited joint mobility antedated the diagnosis of diabetes, and this makes the role of glycaemic control difficult to assess. Long term glycaemic control (as assessed by mean blood glucose or $\mathrm{HbA}_{1 \mathrm{c}}$ values), however, was the same in the two diabetic groups (with and without limited joint mobility).

Most of the patients were middle aged, in whom non-insulin dependent diabetes is more common, and it is therefore surprising that a higher percentage of those with limited joint mobility required insulin treatment. Also of interest is the observation that women were more commonly affected than men, despite the rougher occupational exposure of the latter. Indeed, most often affected were the petty traders; farmers exposed continually to hand trauma were affected in only $23 \%$ of cases. This confirms that our observations were not influenced by trauma or occupation of the subjects.

The mean duration of diabetes in those with limited joint mobility was $6.5(5.8)$ years and 11 had been diabetic for longer than 10 years. Indeed, the range of diabetes' duration was one month to 26 years. This makes the role of diabetes' duration in the genesis of limited joint mobility difficult to assess, but it does suggest, as in previous studies, ${ }^{25}$ that diabetes may be unimportant. Also of note is the fact that duration of diabetes was similar in the patients without limited joint mobility.

Our observation on retinopathy is similar to that in Caucasians. ${ }^{25}$ Proliferative retinopathy is generally uncommon in Nigerian diabetic patients, ${ }^{13}$ and background retinopathy was still quite often seen in those with limited joint mobility. Neuropathy was not more common in our diabetics with limited joint mobility than in those without. This was considered surprising, especially as the presence of limited joint mobility consistently predicted the presence of neuropathy in the reports on Caucasian diabetics. ${ }^{2514}$ Also interesting is the increased association of limited joint mobility with cataracts. This was not specifically ascertained in the earlier reports. The pathogenesis of cataracts and neuropathy is similar in diabetics, being related to increased activation of the aldose reductase pathway. ${ }^{15}$ Cataracts and microvascular complications, however, may also develop from the increased non-enzymatic glycation either of collagen or of lens crystallina. ${ }^{16}$ This last process also occurs but is of less significance in nervous tissue. ${ }^{16}$ Our findings of increased association of limited joint mobility with cataracts and retinopathy may indicate, therefore, that changes in collagen predominantly cause the joint abnormalities, at least in Nigerian diabetics. This is contrary to a report in Caucasians that non-enzymatic glycation of collagen was similar in diabetic patients with or without limited joint mobility and hence was unimportant in the genesis of limited joint mobility in diabetes. ${ }^{17}$ The reduced prevalence of albuminuria is not in keeping with this speculation as nephropathy is also thought to be due to increased glycation of the glomerular basement membrane. ${ }^{7}$ Our recent studies, however, suggest that nephropathy is relatively uncommon in Nigerian diabetics (table). Moreover, the observation of lack of association between nephropathy and limited joint mobility is not new, having been reported in Caucasians. ${ }^{1}$ It suggests that other factors contribute to the genesis of diabetic complications, and reinforces the earlier suggestion ${ }^{10}$ that racial differences may affect the predictive value of the presence of limited joint mobility on diabetic long term complications.

Ours results suggest an increased prevalence of retinopathy and cataracts in diabetic patients with limited joint mobility. Tests for limited joint mobility are simply performed and thus could be useful in identifying the subgroup of diabetics likely to develop severe complications. This would permit closer monitoring of such patients.

We gratefully acknowledge the help and support of the resident medical and nursing staff of the diabetic unit of the University College Hospital, Ibadan, and thank $\mathrm{Mr}$ Babatunde College Hospital, Ibadan, and th
Ogundiran, who typed the manuscript.

1 Starkman H S, Gleason R E, Rand L I, Miller D E, Soeldner $\mathrm{J}$. Limited joint mobility of the hand in patients with S. Limited joint mobility of the hand in patients with Rheum Dis 1986; 45: 130-5.

2 Rosenbloom A L, Silverstein J H, Lezotte D C, Richardson $\mathrm{K}$. McCallum M. Limited joint mobility in childhood diabetes mellitus indicates increased role for microvascular disease. $N$ Engl f Med 1981; 305: 191-4. 3 Starkman H, Brink S. Limited joint mobility of the hand in type I diabetes mellitus. Diabetes Care 1982; 5: 534-6.

4 Jung Y, Hohmann T C, Gerneth J A, et al. Diabetic hand syndrome. Metabolism 1971; 20: 1008-15.

5 Fitzcharles M A, Duby S, Waddell R W, Banks E, Karsh J. Limitation of joint mobility (cheiroarthropathy) in adult Limitation of joint mobity (chetic patients. Ann Rheum Dis 1984; 43: 251-7.

6 Francis M J O, Ellis J P, Hockaday T D R. Skin collagen in diabetes mellitus in relation to treatment. Proceedings of the Royal Society of Medicine 1974; 67: 35-6.

7 Osterby R. Structural changes in the diabetic kidney. Clin Endocrinol Metab 1986; 15: 733-51.

8 Chapple M, Jung R T, Francis J, Webster J, Kohner E M Bloom S R. Joint contractures and diabetic retinopathy. Postgrad Med F 1983; 59: 291-4.

9 World Health Organization expert committee. Diabetes mellitus. Geneva: WHO, 1985. (Technical Report Series 727.

10 Rossi P, Fossaluzzo V. Diabetic cheiroarthropathy in adul non-insulin dependent diabetics. Ann Rheum Dis 1985; 44 141-2.

11 Osuntokun B $O$, Akinkugbe F M, Francis T I, Reddy S, Taylor G O L. Diabetes mellitus in Nigerians: a study of Taylor G O L. Diabetes mellitus in Nigerians: a study of 832 patient $295-312$.

12 Osuntokun B O. Hypertension in Nigerian diabetic patients. Afr F Med Sci 1972; 3: 1-5.

13 Osuntokun B O. Diabetic retinopathy in Nigerians. A study of 758 patients. $\mathrm{Br} \mathrm{F}$ Ophthalmol 1969; 53: 652-63.

14 Anonymous. Diabetic skin, joints and eyes-How are they related? [Editorial]. Lancet 1987; ii: 313-4

15 Greene D A, Lattimer S A. Action of sorbinil in diabetic peripheral nerve. Relationship of polyol (sorbitol) pathway inhibition to a myo-inositol-mediated defect in sodiumpotassium ATPase activity. Diabetes 1984; 33: 712-6. 16 Monnier V M, Cerami A. Non-enzymatic glycosylation and 1982; 11: 431-52.

17 Lyons T J, Kennedy L. Non-enzymatic glycosylation of skin collagen in patients with type 1 (insulin-dependent) diabetes mellitus and limited joint mobility. Diabetes 1985; 28: 2-5. 